\title{
Engagement of the insulin-sensitive pathway in the stimulation of glucose transport by $\alpha$-lipoic acid in 3T3-L1 adipocytes
}

\author{
K. Yaworsky ${ }^{1}$, R.Somwar ${ }^{1}$, T. Ramlal ${ }^{1}$, H.J. Tritschler ${ }^{2}$, A. Klip ${ }^{1}$ \\ ${ }^{1}$ Programme in Cell Biology, The Hospital for Sick Children, Toronto, Ontario, Canada \\ ${ }^{2}$ ASTA-Medica, Frankfurt, Germany
}

\begin{abstract}
Aims/hypothesis. A natural cofactor of mitochondrial dehydrogenase complexes and a potent antioxidant, $\alpha$-lipoic acid improves glucose metabolism in people with Type II (non-insulin-dependent) diabetes mellitus and in animal models of diabetes. In this study we investigated the cellular mechanism of action of $\alpha$-lipoic acid in 3T3-L1 adipocytes.

Methods. We treated 3T3-L1 adipocytes with $2.5 \mathrm{mmol} / \mathrm{l} \mathrm{R}(+) \alpha$-lipoic acid for 2 to $60 \mathrm{~min}$, followed by assays of: 2-deoxyglucose uptake; glucose transporter 1 and 4 (GLUT1 and GLUT4) subcellular localization; tyrosine phosphorylation of the insulin receptor or of the insulin receptor substrate- 1 in cell lysates; association of phosphatidylinositol 3-kinase activity with immunoprecipitates of proteins containing phosphotyrosine or of insulin receptor substrate-1 using a in vitro kinase assay; association of the p85 subunit of phosphatidylinositol 3-kinase with phosphotyrosine proteins or with insulin receptor substrate-1; and in vitro activity of immunoprecipitated Akt1. The effect of R $(+) \alpha$-lipoic acid was also compared with that of $\mathrm{S}(-) \alpha$-lipoic acid.
\end{abstract}

Results. Short-term treatment of 3T3-L1 adipocytes with $\mathrm{R}(+) \alpha$-lipoic acid rapidly stimulated glucose uptake in a wortmannin-sensitive manner, induced a redistribution of GLUT1 and GLUT4 to the plasma membrane, caused tyrosine phosphorylation of insulin receptor substrate- 1 and of the insulin receptor, increased the antiphosphotyrosine-associated and insulin receptor substrate- 1 associated phosphatidylinositol 3-kinase activity and stimulated Akt activity.

Conclusion/interpretation. These results indicate that $\mathrm{R}(+) \alpha$-lipoic acid directly activates lipid, tyrosine and serine/threonine kinases in target cells, which could lead to the stimulation of glucose uptake induced by this natural cofactor. These properties are unique among all agents currently used to lower glycaemia in animals and humans with diabetes. [Diabetologia (2000) 43: 294-303]

Keywords $\alpha$-Lipoic acid, glucose transport, phosphatidylinositol 3-kinase, Akt, subcellular fractionation, 3T3-L1 adipocytes, insulin receptor.
Received: 1 April 1999 and in revised form: 13 September 1999

Corresponding author: A. Klip, PhD, Programme in Cell Biology, The Hospital for Sick Children, 555 University Avenue, Toronto, Ont., M5G 1X8, Canada

Abbreviations: GLUT, glucose transporter; PI3K, phosphatidylinositol 3-kinase; Akt/PKB, protein kinase B; LA, $\alpha$-lipoic acid; PM, plasma membrane; HDM, high-density microsomes; LDM, low-density microsomes; PVDF, polyvinylidene diflouride.
Insulin spelling regulates glucose uptake into fat and muscle cells through the recruitment of glucose transporter (GLUT)4 from an intracellular membrane storage pool to the plasma membrane [1-3]. The first critical step in the stimulation of glucose transport is activation of the insulin receptor intrinsic tyrosine kinase. The activated receptor phosphorylates endogenous substrate proteins, primarily members of the insulin receptor substrate (IRS) family [4]. Tyrosine phosphorylation within multiple YXXM and YMXM motifs on the IRS proteins provide docking 
sites for Src-homology 2 domain-containing proteins. This facilitates the recruitment and the modulation of the regulatory or catalytic activities of a variety of signalling proteins including the $\mathrm{p} 85$ regulatory subunits (p85) of type I phosphatidylinositol 3-kinase $(\mathrm{PI} 3 \mathrm{~K})[5,6]$. Binding of $\mathrm{p} 85$ to IRS proteins activates the associated p110 catalytic subunit of PI3K which in turn catalyses the phosphorylation of phosphoinositides at the D3 position of the inositol ring [7]. Activation of PI3K has been shown to be necessary for insulin-mediated GLUT4 translocation [8-12]. One of the downstream effectors of PI3K is the protein serine/threonine kinase Akt/protein kinase B (PKB). Activation of Akt causes GLUT4 translocation in L6 skeletal muscle cells [13, 14], 3T3-L1 adipocytes [15] and isolated rat adipocytes [16]. A role for Akt in the stimulation of glucose transport by insulin in L6 muscle cells has now been confirmed using a dominant negative mutant construct [17].

There is considerable evidence that a defect in glucose transport is responsible for the acquired insulin resistance of glucose uptake observed in diabetes [18]. This metabolic impairment could conceivably be explained by a variety of defects in GLUT4 regulation including alterations in GLUT4 expression and translocation, defects in the insulin signalling pathway and alterations in the temporal and spatial pattern of signalling molecules. Current antidiabetic therapeutic strategies to reduce glycaemia involve pharmacological agents which promote insulin release (sulphonylureas), curb hepatic glucose output (biguanides) or increase gene expression in fat cells (thiazolidinediones) [19-22]. These compounds also have secondary peripheral effects, such as the stimulation of glucose transport into insulin-responsive tissues.

A new agent that could be useful in the control of glycaemia is $\alpha$-lipoic acid (thioctic acid), a potent biological antioxidant and a natural cofactor of mitochondrial dehydrogenase complexes involved in carbohydrate metabolism [23, 24]. It has been beneficial in the treatment of diabetic neuropathy [25]. In addition, treatment with $\alpha$-lipoic acid enhanced insulinstimulated glucose metabolism in animal models of diabetes [26-28]. Moreover, short-term and repeated treatment with $\alpha$-lipoic acid improved insulin-stimulated glucose disposal in subjects with Type II (noninsulin-dependent) diabetes mellitus [29-31]. In agreement with previous studies in isolated-diaphragm [32] and perfused-heart preparations [33] we have shown that $\alpha$-lipoic acid rapidly stimulates glucose transport into L6 skeletal muscle cells in culture [34].

Stimulation of glucose transport by a physiologically relevant compound such as $\alpha$-lipoic acid warrants investigation into its mechanism of action. Here we show that in 3T3-L1 adipocytes $\alpha$-lipoic acid stimulates glucose transport through the rapid translocation of GLUT1 and GLUT4. Tyrosine phosphorylation of the insulin receptor and IRS-1 in 3T3$\mathrm{L} 1$ adipocytes were increased by $\alpha$-lipoic acid. The activities of PI3K and Akt were also increased in response to $\alpha$-lipoic acid. These unique metabolic actions of $\alpha$-lipoic acid, including the rapid stimulation of glucose transport through the engagement of components of the insulin signalling pathway, support the potential use of $\alpha$-lipoic acid as an antidiabetic agent.

\section{Materials and methods}

Materials. Dulbecco's modified Eagles medium (DMEM), calf serum (CS), fetal bovine serum (FBS) and other tissue culture reagents were purchased from GIBCO/BRL (Burlington, Ont., Canada). We obtained R (+) $\alpha$-lipoic acid and $\mathrm{S}(-) \alpha$-lipoic acid from ASTA Medica (Frankfurt, Germany). Human insulin (Humulin R) was obtained from Eli Lilly Canada (Toronto, Ont., Canada). Protein A Sepharose and protein G Sepharose were from Pharmacia (Uppsala, Sweden). The antibody to the $\alpha$ subunit of the insulin receptor (ARS-2) was a kind gift from Dr. C. Yip (Department of Physiology, University of Toronto). Polyclonal anti-Akt1 (C-20) and monoclonal anti-phosphotyrosine (PY99) antibody were purchased from Santa Cruz Biotechnology (Santa Cruz, Calif., USA). Polyclonal anti-IRS-1, anti-p85, monoclonal anti-phosphotyrosine antibodies and Akt substrate peptide (Crosstide) were from Upstate Biotechnology (Lake Placid, N. Y., USA). Polyclonal anti-GLUT1 and anti-GLUT4 glucose transporter antisera were from East Acres Laboratories (Southbridge, Mass., USA). Purified L- $\alpha$-phosphatidylinositol (PI) was purchased from Avanti Polar Lipids (Alabaster, Ala., USA). Oxalatetreated TLC silica gel $\mathrm{H}$ plates (250 microns) were from Analtech (Newark, Del., USA). Wortmannin was from Sigma (St. Louis, Mo., USA). Microcystin and okadaic acid were from BioMol (Plymouth Meeting, Pa., USA). All other reagents were of the highest analytical grade.

Cell culture, subcellular fractionation and 2-deoxy- ${ }^{3} \mathrm{H}$-D-glucose uptake. Mouse 3T3-L1 fibroblasts were differentiated into adipocytes as described previously [35]. Before all experimental manipulations, 3T3-L1 adipocytes were deprived of serum for at least $3 \mathrm{~h}$. Subcellular fractionation of 3T3-L1 adipocytes grown in 10-cm dishes was carried out as described [36] to obtain plasma membranes (PM), high density microsomes (HDM) and low density microsomes (LDM). Protein $(15 \mu \mathrm{g})$ was resolved by $10 \%$ SDS-PAGE and immunoblotted for GLUT1 or GLUT4. We measured 2-Deoxy- ${ }^{3} \mathrm{H}-\mathrm{D}$-glucose uptake in 3T3-L1 adipocytes as described previously [37]. Each condition was assayed in triplicate.

Immunoprecipitation and assay of phosphatidylinositol 3-kinase activity. The PI3K activity associated with anti-phosphotyrosine immunoprecipitates was determined as described previously for the measurement of PI3K activity associated with IRS-1 immunoprecipitates with the following modifications $[11,38]$ : briefly, 3T3-L1 adipocytes grown in 6-cm dishes were treated with $2.5 \mathrm{mmol} / \mathrm{l} \alpha$-lipoic acid or $100 \mathrm{nmol} / \mathrm{l}$ insulin for the times indicated in Figure 3 and Table 1. Cells were lysed and $500 \mu \mathrm{g}$ of total cellular protein was subjected to immunoprecipitation using $2 \mu \mathrm{g}$ of anti-phosphotyrosine (PY99) or anti-IRS-1 antibodies. The thin layer chromatography plates we used were treated with trans-1,2-diaminocyclohexane$N, N, N^{\prime}, N^{\prime}$-tetra-acetic acid. The PtdIns3P and PtdIns4P (phos- 
phatidylinositol 3- and 4-phosphate, produced by PI3K and PI4K, respectively) were separated in the presence of boric acid [39]. The detection and quantification of [ $\left.{ }^{32} \mathrm{P}\right] \mathrm{PI} 3 \mathrm{P}$ on TLC plates was accomplished using a Molecular Dynamics PhosphorImager System (Sunnyvale, Calif., USA).

Immunoprecipitation and assay of Akt1 protein kinase activity. Immunoprecipitation of Akt and kinase assay was carried out as described previously with the following modifications [38]: briefly, 3T3-L1 adipocytes were grown in $6-\mathrm{cm}$ dishes and treated with $2.5 \mathrm{mmol} / \mathrm{l} \alpha$-lipoic acid or $100 \mathrm{nmol} / \mathrm{l}$ insulin for the times indicated in Table 2 in the absence or presence of $100 \mathrm{nmol} / 1$ wortmannin (30-min pretreatment). The cells were lysed and for each assay, $200 \mu \mathrm{g}$ of total cellular protein was immunoprecipitated with $2 \mu \mathrm{g}$ of anti-Akt1 antibody coupled to $20 \mu \mathrm{l}$ of each a solution of $100 \mathrm{mg} / \mathrm{ml}$ protein A-sepharose and protein G-Sepharose beads.

Detection of insulin receptor substrate-1 phosphorylation and association with the $p 85$ subunit of PI3K. Detection of the level of IRS-1 tyrosine phosphorylation was determined as described previously for L6 myotubes [40] with the following modifications: briefly, 3T3-L1 adipocytes grown in 6-cm dishes were treated with $2.5 \mathrm{mmol} / \mathrm{l} \alpha$-lipoic acid or with $100 \mathrm{nmol} / \mathrm{l}$ insulin for the times indicated in Figure 5, lysed and $500 \mu \mathrm{g}$ of total cellular protein was immunoprecipitated with $2 \mu \mathrm{g}$ antiIRS-1 antibody. Proteins were resolved by $7.5 \%$ SDS-PAGE and then electrotransferred onto polyvinylidene difluoride (PVDF) membranes. The blots were probed with either antiphosphotyrosine antibody (monoclonal, 1:5000 dilution) or anti-p85 antibody (polyclonal, 1:1000 dilution). Proteins were detected by the enhanced chemiluminescence method using sheep anti-mouse or goat anti-rabbit immunoglobulin conjugated to horseradish peroxidase (1:2000 dilution), respectively. Autoradiograms of $\mathrm{x}$-ray films exposed to produce bands within the linear range for quantification were scanned in a Microtek ScanMaker IIHR (Microtek, Redondo Beach, Calif., USA) and quantified using the computer software NIH Image (National Institutes of Health, Bethesda, Md., USA).

Detection of insulin receptor phosphorylation. We grew 3T3-L1 adipocytes in $6-\mathrm{cm}$ dishes and treated them with $2.5 \mathrm{mmol} / \mathrm{l} \alpha$ lipoic acid or with $100 \mathrm{nmol} / \mathrm{l}$ insulin for the times indicated in Figure 4 . Then they were rinsed twice with ice-cold PBS containing $100 \mathrm{mmol} / \mathrm{l}$ sodium vanadate $\left(\mathrm{Na}_{3} \mathrm{VO}_{4}\right)$ and lysed with $0.5 \mathrm{ml}$ of lysis buffer [ $150 \mathrm{mmol} / \mathrm{l} \mathrm{NaCl}, 50 \mathrm{mmol} / \mathrm{l}$ TRIS, $\mathrm{pH}$ $7.2,0.25 \%(\mathrm{w} / \mathrm{v})$ deoxycholate, $1 \%(\mathrm{w} / \mathrm{v})$ nonidet $\mathrm{P}-40$, $10 \mathrm{mmol} / \mathrm{l}$ sodium pyrophosphate, $100 \mathrm{mmol} / \mathrm{l} \mathrm{NaF}, 2 \mathrm{mmol} / \mathrm{l}$ EDTA, $1 \mathrm{mmol} / 1 \mathrm{Na}_{3} \mathrm{VO}_{4}$ containing a mixture of protease inhibitors $(1 \mu \mathrm{mol} / \mathrm{l}$ leupeptin, $1 \mu \mathrm{mol} / \mathrm{l}$ pepstatin $\mathrm{A}$, and $200 \mu \mathrm{mol} / \mathrm{l}$ phenylmethylsulphonyl fluoride]. Of the total cellular protein $1 \mathrm{mg}$ was incubated with $0.5 \mathrm{mg} / \mathrm{ml}$ anti-ARS- 2 antibody for $2-3 \mathrm{~h}$ at $4{ }^{\circ} \mathrm{C}$ under constant rotation, followed by a 1 -h incubation with $30 \mu \mathrm{l}$ of a solution of $100 \mathrm{mg} / \mathrm{ml}$ protein A Sepharose beads. Immunocomplexes were washed five times with phosphate-buffered saline containing $100 \mu \mathrm{mol} / 1 \mathrm{Na}_{3} \mathrm{VO}_{4}$ and $0.1 \%$ nonidet P-40. Pellets were resuspended and proteins were resolved by $7.5 \%$ SDS-PAGE and electrotransferred onto PVDF membranes. The blots were probed with antiphosphotyrosine antibody (monoclonal, 1:5000 dilution) as described above.

Statistical analysis. Statistical analysis was done using the analysis of variance test (ANOVA, Fisher's multiple comparisons test) or the paired two-tailed $z$ test. A $p$ value less than 0.05 was considered significant.

\section{Results}

$R(+) \alpha$-Lipoic acid stimulates the translocation of GLUT1 and GLUT4 to the plasma membrane. We have previously shown that short-term treatment of L6 myotubes and 3T3-L1 adipocytes with R $(+) \alpha-$ lipoic acid for 60 min leads to the stimulation of glucose transport, similar to the action of insulin [34]. Here we examined the effect of $\mathrm{R}(+) \alpha$-lipoic acid on the subcellular distribution of the glucose transporters GLUT1 and GLUT4. Equal amounts of protein $(15 \mu \mathrm{g})$ from each fraction were resolved by $10 \%$ SDS-PAGE and immunoblotted for GLUT1 or GLUT4. Treatment of 3T3-L1 adipocytes with R (+) $\alpha$-lipoic acid for $60 \mathrm{~min}$ augmented GLUT1 in the plasma membrane fraction (PM) by $2.1 \pm 0.4$-fold $(p<0.05)$, relative to that in the PM of untreated cells (control, C) (Fig.1). Insulin caused a similar gain in GLUT1 in the plasma membrane $(2.1 \pm 0.3$-fold, $p<0.001)$. Both $\mathrm{R}(+) \alpha$-lipoic acid and insulin reduced GLUT1 content in the low-density microsomal fraction (LDM) of 3T3-L1 adipocytes, with insulin being the more effective agent $[\mathrm{R}(+) \alpha$-lipoic acid: $30 \%$ reduction $(p<0.05)$; insulin: $61 \%$ reduction $(p<0.001)]$.

A $2.9 \pm 0.9$-fold $(p<0.05)$ increase in GLUT4 content in the PM, relative to PM of control cells was caused by $\mathrm{R}(+) \alpha$-lipoic acid (Fig.2). Insulin increased GLUT4 at the plasma membrane by $4.8 \pm 1.6$-fold $(p<0.05)$ above control. There was no statistically significant difference between the amount of GLUT4 in the PM of cells treated with insulin and those treated with $\mathrm{R}(+) \alpha$-lipoic acid. A reduction in GLUT4 in the LDM in response to R $(+)$ $\alpha$-lipoic acid $(16 \%, p<0.05)$ and insulin $(37 \%$, $p<0.001)$ was also observed.

Concentration-dependent stimulation of glucose transport by $R(+) \alpha$-lipoic acid. A dose-dependent stimulation of 2-deoxyglucose uptake into 3T3-L1 adipocytes was elicited by R (+) $\alpha$-lipoic acid. Treatment of 3T3-L1 adipocytes with increasing concentrations of $\mathrm{R}(+) \alpha$-lipoic acid led to a dose-dependent increase in glucose transport which was first observed at $1 \mathrm{mmol} / \mathrm{l} \mathrm{R}(+) \alpha$-lipoic acid (57\%), and continued to increase up to the highest concentration tested of $5 \mathrm{mmol} / \mathrm{l}(100 \%$ ) (Fig. 2$)$. In all subsequent experiments, the effects of $\mathrm{R}(+) \alpha$-lipoic acid were determined at a concentration of $2.5 \mathrm{mmol} / \mathrm{l}$, which is in the mid range of the concentration-dependent stimulation of glucose uptake by $\mathrm{R}(+) \alpha$-lipoic acid. The sensitivity to $\mathrm{R}(+) \alpha$-lipoic acid in these 3 T3-L1 adipocytes is reminiscent of that measured previously for L6 myotubes [34].

Wortmannin prevents the stimulation of glucose transport by $R(+) \alpha$-lipoic acid. We examined the possible engagement of molecules that are known to mediate 
A
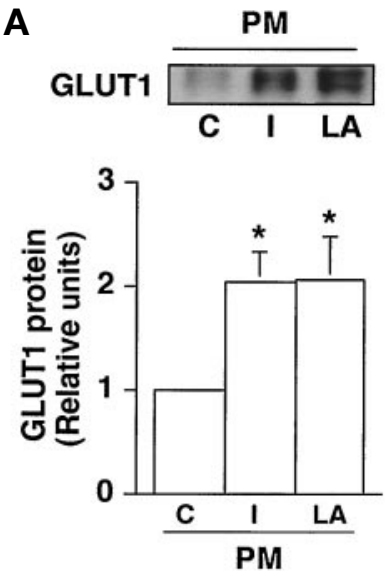

B
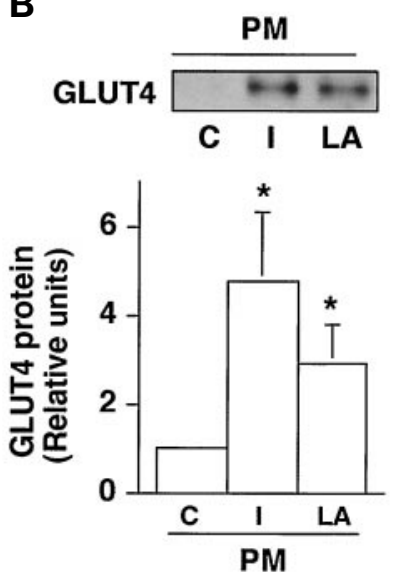
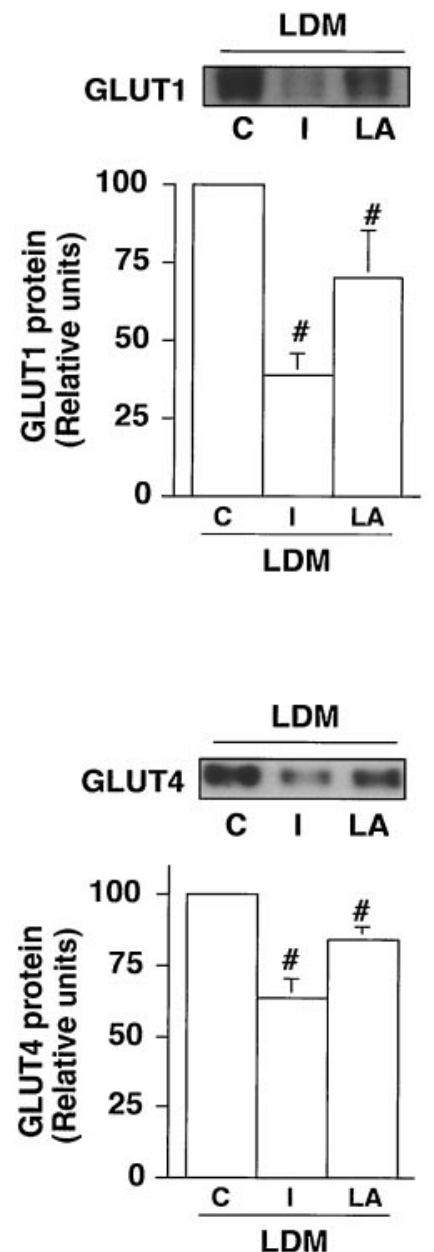

Fig. 1 A, B. Effect of R (+) $\alpha$-lipoic acid on the distribution of glucose transporters. Plasma membranes (PM) and low density microsomes (LDM) were isolated from cells that were treated for $1 \mathrm{~h}$ with $2.5 \mathrm{mmol} / \mathrm{l} \mathrm{R}(+) \alpha$-lipoic acid (LA) or for $20 \mathrm{~min}$ with $100 \mathrm{nmol} / \mathrm{l}$ insulin (I). Protein $(15 \mu \mathrm{g})$ was resolved by $10 \%$ SDS-PAGE and immunoblotted for GLUT1 (A) or GLUT4 (B). Immunoreactive bands were scanned and protein quantified. A representative immunoblot is shown. Results are the means \pm SEM of four experiments and are expressed in relative units, with the average reading of control (C) PM assigned a value of 1 . *Significantly different from control PM, $p<0.05$ ( $z$ test, two-tailed). "Significantly different from control LDM, $p<0.05$ ( $z$ test, two-tailed).

insulin action to explain the mechanism underlying the stimulation of glucose transport by $\mathrm{R}(+) \alpha$-lipoic acid. Glucose transport was stimulated by R $(+) \alpha-$ lipoic acid in 3T3-L1 adipocytes by four-fold [basal: 4.2 pmol $\cdot \mathrm{min}^{-1} \cdot \mathrm{mg}^{-1}, \mathrm{R}(+) \alpha$-lipoic acid: $17.1 \mathrm{pmol} \cdot$ $\mathrm{min}^{-1} \cdot \mathrm{mg}^{-1}$ protein] (Fig. 2). Pretreatment of 3T3-L1 adipocytes with $100 \mathrm{nmol} / \mathrm{l}$ wortmannin for $30 \mathrm{~min} \mathrm{ab}-$ rogated the ability of $\mathrm{R}(+) \alpha$-lipoic acid to stimulate glucose transport [control: $3.7 \mathrm{pmol} \cdot \mathrm{min}^{-1} \cdot \mathrm{mg}^{-1}$ protein, $\mathrm{R}(+) \alpha$-lipoic acid + wortmannin: $2.7 \mathrm{pmol}$. $\mathrm{min}^{-1} \cdot \mathrm{mg}^{-1}$ protein]. Similarly, wortmannin abolished insulin-stimulated glucose transport (insulin + wortmannin: $3.4 \mathrm{pmol} \cdot \mathrm{min}^{-1} \cdot \mathrm{mg}^{-1}$ protein).
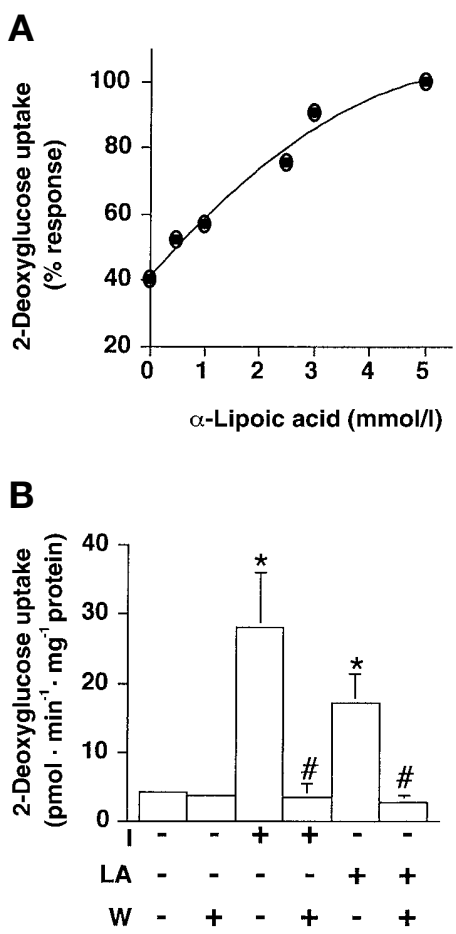

Fig. 2. A Concentration dependence of the action of $\mathrm{R}(+) \alpha-$ lipoic acid on 2-deoxyglucose uptake. Cells grown in 12-well dishes were treated for $60 \mathrm{~min}$ with increasing concentrations of R (+) $\alpha$-lipoic acid (LA). Subsequently 2-deoxy- ${ }^{3} \mathrm{H}$-D-glucose uptake was determined over $5 \mathrm{~min}$. Results represent the means \pm SEM of four experiments. The results are expressed as the per cent $(\%)$ response in comparison with the highest stimulation of glucose transport elicited at $5 \mathrm{mmol} / \mathrm{l} \mathrm{R}(+) \alpha$-lipoic acid. B Effect of wortmannin on R $(+) \alpha$-lipoic acid-stimulated glucose transport. Cells were treated for $60 \mathrm{~min}$ with $2.5 \mathrm{mmol} / \mathrm{l} \mathrm{R}(+) \alpha$-lipoic acid (LA) or with $100 \mathrm{nmol} / \mathrm{l}$ insulin (I) for $30 \mathrm{~min}$, in the absence or presence of $100 \mathrm{nmol} / \mathrm{l}$ wortmannin (W, $30 \mathrm{~min}$ pretreatment). Results represent the means \pm SEM of three to seven experiments. *Significantly different from control, $p<0.05$ (ANOVA, Fisher's multiple comparisons test). "Significantly different from corresponding controls, $p<0.05$ (ANOVA, Fisher's multiple comparisons test)

Activation of PI3K by $R(+) \alpha$-lipoic acid. The results obtained above with wortmannin suggested that $\mathrm{R}(+) \alpha$-lipoic acid engages PI3K in its mechanism of action. To further explore this possibility, we determined the effect of $\mathrm{R}(+) \alpha$-lipoic acid on PI3K activity associated with anti-phosphotyrosine immunoprecipitates, using an in vitro kinase assay (Table 1$)$. Treatment of 3T3-L1 adipocytes with R $(+) \alpha$-lipoic acid raised the phosphotyrosine-associated PI3K activity to $4.0 \pm 0.6$-fold $(p<0.05)$ at $5 \mathrm{~min}$, relative to control and to $4.4 \pm 0.90$-fold $(p<0.05)$ at $10 \mathrm{~min}$, relative to control. By 20 and $30 \mathrm{~min}, \mathrm{PI} 3 \mathrm{~K}$ activity remained high but was not significantly different from basal activity $(3.4 \pm 0.2$ and $2.2 \pm 0.3$, respectively). Insulin treatment $(5 \mathrm{~min})$ induced a greater increase in the activity of PI3K associated with phosphotyrosine $(13.2 \pm 1.3$-fold, $p<0.0001)$ than that achieved with $\mathrm{R}(+) \alpha$-lipoic acid. In vitro treatment with wort- 
Table 1. Activation of PI3K by R (+) $\alpha$-lipoic acid

\begin{tabular}{llcc}
\hline Stimulus & IP & Time, min & $\begin{array}{l}\text { Fold increase } \\
\text { in PI3K activity }\end{array}$ \\
\hline C & anti-PY & 0 & 1.0 \\
LA & anti-PY & 5 & $4.0 \pm 0.6^{\mathrm{a}}$ \\
LA & anti-PY & 10 & $4.4 \pm 0.9^{\mathrm{a}}$ \\
LA & anti-PY & 20 & $3.4 \pm 0.2$ \\
LA & anti-PY & 30 & $2.2 \pm 0.3$ \\
I & anti-PY & 5 & $13.2 \pm 1.3^{\mathrm{a}}$ \\
- & non-specific IgG & - & $0.36 \pm 0.2$ \\
\hline
\end{tabular}

Phosphatidylinositol 3-kinase activity associated with antiphosphotyrosine immunoprecipitates was determined using the in vitro kinase assay described in Materials and methods. Results represent the means \pm SEM of four independent experiments and are expressed as the fold-stimulation relative to unstimulated controls.

${ }^{a}$ Significantly different from control, $p<0.05$ (ANOVA, Fisher's multiple comparisons test). The cpm of control (basal) PI3K activity of a representative experiment were 413582 (1.0-fold) and the cpm of a blank, irrelevant IgG immunoprecipitate were 67846 (0.16-fold). R (+) $\alpha$-Lipoic acid, LA; insulin, I; immunoprecipitation, IP; anti-phosphotyrosine, anti PY

Table 2. Activation of Akt1 by R $(+) \alpha$-lipoic acid

\begin{tabular}{llcll}
\hline Stimulus & IP & Time (min) & $\begin{array}{l}\text { Fold increase in Akt1 } \\
\text { kinase activity }\end{array}$ \\
\cline { 3 - 5 } & & & $\begin{array}{l}\text { - Wort- } \\
\text { mannin }\end{array}$ & $\begin{array}{l}\text { + Wort- } \\
\text { mannin }\end{array}$ \\
\hline C & anti-Akt1 & 0 & 1.0 & $1.2 \pm 0.2$ \\
LA & anti-Akt1 & 5 & $2.4 \pm 0.5^{\mathrm{a}}$ & $1.1 \pm 0.1^{\mathrm{c}}$ \\
LA & anti-Akt1 & 10 & $2.2 \pm 0.9^{\mathrm{a}}$ & $0.9 \pm 0.2$ \\
LA & anti-Akt1 & 20 & $1.6 \pm 0.2$ & $0.9 \pm 0.1$ \\
LA & anti-Akt1 & 30 & $1.7 \pm 0.2$ & $1.0 \pm 0.1$ \\
I & anti-Akt1 & 5 & $4.2 \pm 0.8^{\mathrm{a}}$ & $1.0 \pm 0.1^{\mathrm{b}}$ \\
- & non-specific IgG & - & $0.7 \pm 0.1$ & - \\
\hline
\end{tabular}

Akt1 was immunoprecipitated and kinase activity subsequently determined using a in vitro kinase assay as described in Materials and methods. Results represent the means \pm SEM of three to five independent experiments and are expressed as the fold-stimulation relative to unstimulated controls. ${ }^{\text {a Signi- }}$ ficantly different from control, $p<0.05$ (ANOVA, Fisher's multiple comparisons test). ${ }^{\mathrm{b}}$ Significantly different from insulin (I, $5 \mathrm{~min}$ ), $p<0.0001$ (ANOVA, Fisher's multiple comparisons test). ${ }^{c}$ Significantly different from R $(+) \alpha$-lipoic acid (LA, $5 \mathrm{~min}$ ), $p<0.05$ (ANOVA, Fisher's multiple comparisons tests). The cpm of basal (control) Akt1 activity of one representative experiment were 1099 (1.0-fold) and the cpm of a blank, non-specific IgG immunoprecipitate were 534 (0.49fold). R (+) $\alpha$-Lipoic acid, LA; insulin, I; immunoprecipitation, IP

mannin $(100 \mathrm{nmol} / \mathrm{l})$ prevented the insulin and $\mathrm{R}(+)$ $\alpha$-lipoic acid stimulation of PI3K activity (data not shown).

Effect of $R(+) \alpha$-lipoic acid on Akt1 activity. The regulation of Akt1 by insulinomimetic agents has not been explored, despite the implication of this enzyme in the stimulation of glucose transport by insulin $[15$, 17, 41]. Table 2 shows the ability of $\mathrm{R}(+) \alpha$-lipoic acid to increase the activity of Akt1 by $2.4 \pm 0.5$-fold $(p<0.05)$ in $5 \mathrm{~min}$ and by $2.2 \pm 0.9$-fold $(p<0.05)$ in $10 \mathrm{~min}$. Activation of Akt1 by R (+) $\alpha$-lipoic acid subsided in time, so that at 20 and $30 \mathrm{~min}$ it no longer reached statistical significance $(1.6 \pm 0.2$ and $1.7 \pm 0.2$, respectively). Hence, the rise in Akt1 activation stimulated by $R(+) \alpha$-lipoic acid followed a similar temporal pattern to the stimulation of PI3K activity. By comparison, Akt1 activity was increased $4.2 \pm 0.8$-fold after $5 \mathrm{~min}$ of exposure to insulin $(p<0.0001)$. Pretreatment of the cells with 100 nmol/l wortmannin prevented the activation of Akt1 by both $\mathrm{R}(+) \alpha$-lipoic acid and insulin. This finding suggests that the activation of Akt1 by $R(+) \alpha$-lipoic acid is downstream of PI3K.

Effect of $R(+) \alpha$-lipoic acid on IRS-1 phosphorylation and PI3K activity. Given that $\alpha$-lipoic acid induced the activation of PI3K bound to phosphotyrosine-containing proteins, we explored whether the compound affected tyrosine phosphorylation of IRS1 or PI3K activity associated with it. Insulin-receptor substrate- 1 is the predominant IRS protein in differentiated 3T3-L1 adipocytes and it could be a major mediator of the metabolic actions of insulin in these cells [42-44]. Immunoprecipitates of IRS-1 from 3T3-L1 adipocytes that were treated with R (+) $\alpha$-lipoic acid or insulin were resolved by $7.5 \%$ SDSPAGE and immunoblotted with anti-phosphotyrosine antibody. Treatment with $\mathrm{R}(+) \alpha$-lipoic acid for 2 or $5 \mathrm{~min}$ stimulated tyrosine phosphorylation of IRS- 1 by $3.1 \pm 1.1$-fold $(p<0.05)$ or $3.3 \pm 1.1$-fold $(p<0.05)$, compared with the control. By comparison, tyrosine phosphorylation of IRS-1 was stimulated $4.7 \pm 1.3$-fold $(p<0.05)$ by a 2 -min insulin challenge (Fig. 3). Treatment with R (+) $\alpha$-lipoic acid for 5 min considerably stimulated the activity of PI3K activity associated with IRS-1 (8.5 \pm 1.6 -fold) (Fig. 3). Consistent with the stimulation of tyrosine phosphorylation of IRS- 1 by $\mathrm{R}(+) \alpha$-lipoic acid, the stimulation of PI3K caused by R (+) $\alpha$-lipoic acid was still below that achieved by the maximum insulin concentrations $(12.7 \pm 1.9$-fold $)$. These experiments highlight the ability and potency of $\mathrm{R}(+) \alpha$-lipoic acid alone to increase the activity of an enzyme that is central to insulin action and to the stimulation of glucose uptake.

Induction of tyrosine phosphorylation of the insulin receptor by $R(+) \alpha$-lipoic acid in intact cells. Insulin activates the intrinsic tyrosine kinase activity of its receptor, leading to autophosphorylation of tyrosine residues in several regions of the intracellular $\beta$ subunit of the receptor [45]. The activation of the insulin receptor tyrosine kinase activity is necessary for the interaction and subsequent activation of downstream signalling molecules, including IRS-1. To define the involvement of tyrosine kinases in the action of 


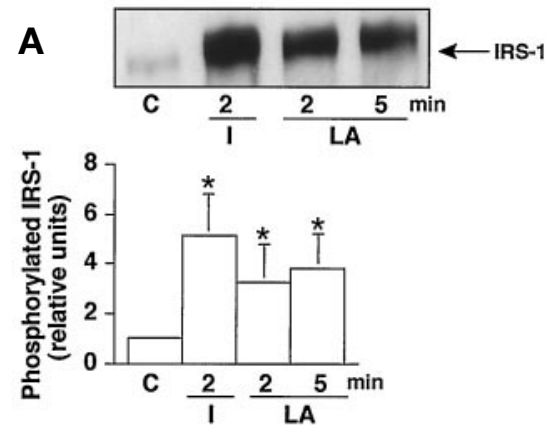

B

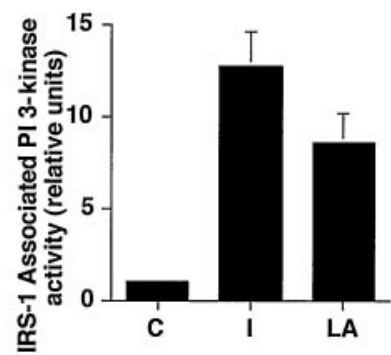

Fig. 3 A, B. Phosphorylation of the insulin receptor substrate-1 (IRS-1) and associated PI3K activity. Total cell lysates were prepared from cells that were treated with $2.5 \mathrm{mmol} / \mathrm{l} \mathrm{R}(+)$ $\alpha$-lipoic acid (LA) or $100 \mathrm{nmol} / \mathrm{l}$ insulin (I). A Insulin receptor substrate-1 was immunoprecipitated from total cell lysates, immunoprecipitates were resolved by $7.5 \%$ SDS-PAGE and immunoblotted with anti-phosphotyrosine antibody. A typical immunoblot is illustrated. Immunoblots from four experiments were scanned and tyrosine phosphorylated IRS-1 quantified. B Activity of PI3K associated with anti-IRS-1 immunoprecipitates was determined using a in vitro kinase assay. The results (means \pm SEM) are expressed in relative units, with the average reading of the controls $(C)$ assigned a value of 1.0. * Significantly different from control, $p<0.05$ ( $z$ test, twotailed)

$\mathrm{R}(+) \alpha$-lipoic acid we explored the possibility that treatment of 3T3-L1 adipocytes with R (+) $\alpha$-lipoic acid activates the insulin receptor itself. Treatment of intact cells with $\mathrm{R}(+) \alpha$-lipoic acid increased tyrosine phosphorylation of the insulin receptor (Fig.4). Despite the noticeable and significant increases in tyrosine phosphorylation of the insulin receptor at 5 and 10 min of $\mathrm{R}(+) \alpha$-lipoic acid treatment compared with the control $(3.9 \pm 1.2$-fold, $p<0.05$ and $4.5 \pm 1.3$-fold, $p<0.05$, respectively) this phosphorylation was lower than that induced by insulin treatment at $5 \mathrm{~min}(15.5 \pm 4.4$-fold, vs control, $p<0.005)$.

Comparison of the action of $R(+)$ and $S(-)$ d-lipoic acid on glucose uptake, on IRS-1 phosphorylation and its association with the $p 85$ subunit of PI3K. The above experiments were all done using the $\mathrm{R}(+)$ isomer of $\alpha$-lipoic acid. To explore whether some of these properties were shared by the $\mathrm{S}(-)$ isomer, we compared the effect of the two isomers on hexose uptake, on IRS-1 phosphorylation and on the associa-

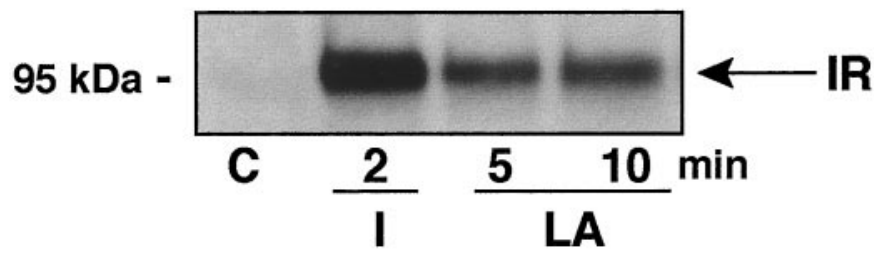

Fig. 4. The effect of R (+) $\alpha$-lipoic acid on in vivo activation of the insulin receptor. Total cell lysates were prepared from cells treated in vivo with $2.5 \mathrm{mmol} / \mathrm{l} \mathrm{R}(+) \alpha$-lipoic acid (LA) or with $100 \mathrm{nmol} / \mathrm{l}$ insulin (I) for the indicated times. The insulin receptor (IR) was immunoprecipitated, resolved by $7.5 \%$ SDSPAGE and immunoblotted with anti-phosphotyrosine antibody. Immunoblots were scanned and insulin receptor protein was quantified. A representative immunoblot of five independent experiments is illustrated.

tion of the p85 subunit of PI3K to tyrosine-phosphorylated IRS-1. Whereas the R (+) compound stimulated 2-deoxyglucose uptake significantly in 3T3-L1 adipocytes, the $\mathrm{S}(-)$ isomer did not cause any statistically significant effect on this variable (Fig.5). The $\mathrm{S}(-)$ isomer was also very ineffective in causing phosphorylation of IRS-1, compared with the $\mathrm{R}(+)$ isomer (Fig. 5). The p85 subunit of PI3K failed to associate with IRS-1 immunoprecipitates of 3T3-L1 adipocytes treated with $S(-) \alpha$-lipoic acid, whereas it showed a positive association in immunoprecipitates of cells treated with the R (+) isomer (Fig.5).

\section{Discussion}

To begin to understand the mechanism underlying the stimulation of glucose transport by $\mathrm{R}(+) \alpha$-lipoic acid in 3T3-L1 adipocytes, we examined the effect of this compound on GLUT1 and GLUT4 redistribution. Subcellular fractionation of 3T3-L1 adipocytes indicated that $\mathrm{R}(+) \alpha$-lipoic acid induced a rapid translocation of GLUT1 and GLUT4 to the plasma membrane, associated with a reduction in these transporters in the low density microsomal membrane fraction. This action of $\mathrm{R}(+) \alpha$-lipoic acid qualitatively resembled the ability of insulin to redistribute GLUT1 and GLUT4. The quantitative differences in the action of $\mathrm{R}(+) \alpha$-lipoic acid and insulin could be due to the quantitative differences in signalling described below. The rapid redistribution of glucose transporters is likely to be the mechanism by which $\mathrm{R}(+) \alpha$-lipoic acid can rapidly stimulate glucose transport into 3T3-L1 adipocytes. To our knowledge, $\mathrm{R}(+) \alpha$-lipoic acid is the only known agent with antidiabetic properties that can directly induce a rapid redistribution of glucose transporters in its target cells, thereby allowing for the subsequent increase in uptake of glucose.

In this study, we show that $\mathrm{R}(+) \alpha$-lipoic acid (1-5 mol/l) rapidly stimulated glucose uptake into 3T3-L1 adipocytes, and we show accompanying 

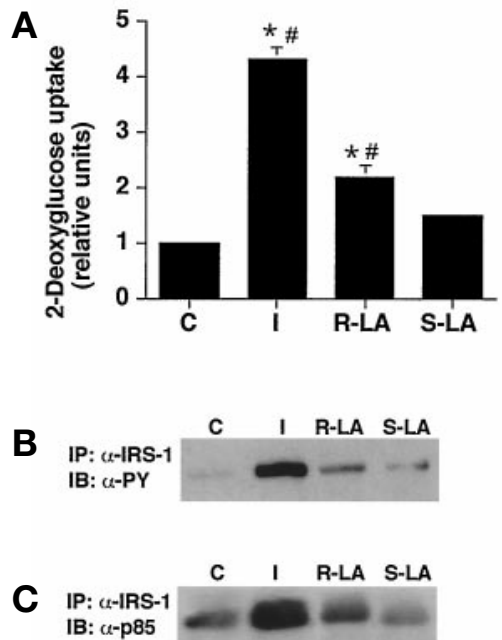

Fig. 5A-C. Comparison of the effect of $\mathrm{R}(+) \alpha$-lipoic acid and S(-) $\alpha$-lipoic acid on 2-deoxyglucose uptake, IRS-1 phosphorylation and association of the p85 subunit of PI3K with IRS-1. A Cells were left untreated (C) or treated for $60 \mathrm{~min}$ with $2.5 \mathrm{mmol} / \mathrm{l} \mathrm{R}(+) \alpha$-lipoic acid (R-LA) or S(-) $\alpha$-lipoic acid (S-LA) or for $30 \mathrm{~min}$ with $100 \mathrm{nmol} / \mathrm{l}$ insulin. Results represent the mean of three experiments. *Significantly different from control, $p<0.05$, "Significantly different from $\mathrm{S}(-) \alpha$-lipoic acid, $p<0.05$ (ANOVA, Fisher's multiple comparisons test). Sample S-LA was not statistically different from sample C, control. Insulin receptor substrate-1 was immunoprecipitated from total cell lysates, immunoprecipitates were resolved by $7.5 \%$ SDS-PAGE and immunoblotted with $\mathbf{B}$ anti-phosphotyrosine $(\alpha-\mathrm{PY})$ or $\mathbf{C}$ anti-p85 antibody. Immunoprecipitation, IP; Immunoblotting, IB

translocation of glucose transporters (using $2.5 \mathrm{mmol} / \mathrm{l} \mathrm{R}(+) \alpha$-lipoic acid). This concentration of $\mathrm{R}(+) \alpha$-lipoic acid is two to seven times higher than the concentration that could reach muscle and fat cells in animals or humans treated with the compound (calculated based on the dose given and the expected volume of blood and extracellular fluid) $[28,29]$. There are two different enantiomers of $\alpha$-lipoic acid; the biologically active $\mathrm{R}(+)$ isoform and the $\mathrm{S}(-)$ isoform. It was shown previously that $\mathrm{R}(+)$ $\alpha$-lipoic acid was more potent than $S(-) \alpha$-lipoic acid in its ability to stimulate glucose uptake in L6 myotubes [34]. In fact, the $\mathrm{S}(-)$ isoform inhibited insulin action [46]. For these reasons, the current study focused on the actions of $\mathrm{R}(+) \alpha$-lipoic acid. When the effect of the $\mathrm{S}(-)$ isomer was tested on 2-deoxyglucose uptake, IRS-1 phosphorylation or on the association of p85 subunit of PI3K to IRS-1, there was no statistically significant effect compared with the action of the $\mathrm{R}(+)$ isomer. Hence, this study further extends the importance of the $\mathrm{R}(+)$ isomer in mimicking some actions of insulin and highlights the relative lack of effect of the $\mathrm{S}(-)$ isomer.

To analyse the signals involved in the stimulation of glucose transport and transporter translocation by $\mathrm{R}(+) \alpha$-lipoic acid, we examined several elements of the insulin signalling cascade. Studies involving the use of selective inhibitors of PI3K [8, 9, 47, 48], dominant negative mutants [49] and overexpression of constitutively active forms of PI3K [50, 51] have shown the need for PI3K in the stimulation of glucose transport by insulin. In our study we show that wortmannin, a relatively specific inhibitor of PI3K, prevents the stimulation of glucose transport by $\mathrm{R}(+)$ $\alpha$-lipoic acid in 3T3-L1 adipocytes. Further, R $(+) \alpha-$ lipoic acid could directly increase PI3K activity associated with anti-phosphotyrosine immunoprecipitates and with anti-IRS-1 immunoprecipitates. These findings suggest that $\mathrm{R}(+) \alpha$-lipoic acid engages components of the insulin signal transduction cascade in its ability to stimulate glucose transport. In contrast to conditions of contractile activity and hypoxia [48], or to agents such as dinitrophenol [52] or vanadium compounds [53] which increase glucose transport independent of the involvement of PI3K, R (+) $\alpha$-lipoic acid has the ability, similar to insulin, to use this enzyme.

In support of the ability of $\mathrm{R}(+) \alpha$-lipoic acid to engage components of the insulin-sensitive pathway, we showed that this compound activated Akt1, a downstream effector of PI3K in the stimulation of glucose transport in muscle cells [17]. Surprisingly, there is little evidence of any effect of agents being capable of stimulating glucose transport on the activation of Akt1. A recent report showed that vanadium compounds activated Akt1 and this activation was inhibited by wortmannin [54]. This is, however, inconsequential for glucose transport because the stimulation of glucose transport by vanadate is wortmannin-insensitive [55]. In contrast, both the stimulation of glucose transport and activation of Akt1 by $\mathrm{R}(+) \alpha$-lipoic acid in 3T3-L1 adipocytes are sensitive to inhibition of PI3K with wortmannin. The engagement by $R(+) \alpha$-lipoic acid of lipid and serine/threonine kinases implicated in the stimulation of glucose transport by insulin lends further support to the notion that $\mathrm{R}(+) \alpha$-lipoic acid targets the insulin-sensitive pathway. It has recently been described that other targets of the products of PI3K, in particular the atypical protein kinase Cs, participate in the stimulation of glucose uptake by insulin in 3T3-L1 adipocytes [56]. There is current debate on the extent of participation of Akt1 and protein kinase $\mathrm{C}$ in insulin action in the different tissues and cell types.

Tyrosine kinases acting upstream of PI3K also represent critical components of the insulin signalling pathway involved in the stimulation of glucose transport. Our results indicate that IRS- 1 tyrosine phosphorylation in 3T3-L1 adipocytes was increased in response to $\mathrm{R}(+) \alpha$-lipoic acid. This suggests that $\mathrm{R}(+)$ $\alpha$-lipoic acid activates an upstream tyrosine kinase. Surprisingly, we found that treatment of 3T3-L1 adipocytes with $\mathrm{R}(+) \alpha$-lipoic acid also increased the ty- 
rosine phosphorylation of the insulin receptor, although to a lesser extent than treatment with insulin.

The basis for the ability of $\mathrm{R}(+) \alpha$-lipoic acid to stimulate glucose transport and glucose transporter translocation remains to be determined. Several recent studies have provided evidence suggesting an association between oxidative stress and diabetes [57-59], and importantly lipoic acid itself has been shown to protect against the loss of insulin action on glucose uptake in a model of in vitro oxidative stress [60]. Thus, it has been suggested that the potent antioxidant and redox-modulating capabilities of $\alpha$-lipoic acid contributes to its metabolic actions. The reduced analogue of $\alpha$-lipoic acid, dihydrolipoic acid (DHLA), was previously shown to stimulate glucose uptake in L6 myotubes to a similar extent as the R $(+)$ isoform [46]. In addition, dithiothreitol, a compound with a high redox potential, caused a negligible and non-statistically significant stimulation of glucose uptake in L6 myotubes [34]. This result suggested that the high redox potential of a compound is not sufficient to increase glucose transport. Potentially, the ability of lipoic acid to function as a cellular antioxidant or its involvement as a cofactor of oxidative metabolism or both could contribute to its ability to stimulate glucose uptake.

In conclusion, we have shown that the physiologically relevant compound $\mathrm{R}(+) \alpha$-lipoic acid induces a rapid redistribution of GLUT1 and GLUT4, leading to stimulation of glucose uptake into 3T3-L1 adipocytes and that the compound stimulates tyrosine, lipid, and serine/threonine kinases. The results suggest that $\mathrm{R}(+) \alpha$-lipoic acid could directly target elements of the insulin signalling pathway, in contrast to the actions of all other agents known to stimulate glucose transport. These unique metabolic actions of $\mathrm{R}(+) \alpha$-lipoic acid, including the rapid stimulation of glucose transport through components of an insulin sensitive pathway, support the potential therapeutic importance of this agent for the treatment of diabetes.

Acknowledgements. The authors wish to thank Drs. P. Bilan and G. Sweeney for continued technical advice and for many helpful comments on the manuscript. This work was supported by the Canadian Diabetes Association and ASTA Medica. K. Yaworsky and R. Somwar are supported by The Hospital for Sick Children Matching Fund Studentship Graduate Scholarships at the University of Toronto.

\section{References}

1. Cushman SW, Wardzala LJ (1980) Potential mechanism of insulin action on glucose transport in the isolated rat adipose cell. J Biol Chem 255: 4758-4762

2. Suzuki K, Kono T (1980) Evidence that insulin causes translocation of glucose transport activity to the plasma membrane from an intracellular storage site. Proc Natl Acad Sci USA 77: 2542-2545
3. Klip A, Ramlal T, Young DA, Holloszy JO (1987) Insulininduced translocation of glucose transporters in rat hindlimb muscles. FEBS Lett 224: 224-230

4. White MF, Maron R, Kahn CR (1985) Insulin rapidly stimulates tyrosine phosphorylation of a Mr 185,000 protein in intact cells. Nature 318: 183-186

5. White MF (1998) The IRS-signalling system: A network of docking proteins that mediate insulin action. Mol Cell Biochem 182: 3-11

6. Shepherd PR, Withers DJ, Siddle K (1998) Phosphoinositide 3-kinase:the key switch mechanism in insulin signalling. Biochem J 333: 471-490

7. Toker A, Cantley LC (1997) Signalling through the lipid products of phosphoinisitide-3-OH kinase. Nature 387: 673-676

8. Cheatham B, Vlahos CJ, Cheatham L, Wang L, Blenis J, Kahn CR (1994) Phosphatidylinositol 3-kinase activation is required for insulin stimulation of pp70 S6 kinase, DNA synthesis, and glucose transporter translocation. Mol Cell Biol 14: 4902-4911

9. Okada T, Kawano Y, Sakakibara T, Hazeki O, Ui M (1994) Essential role of phosphatidylinositol 3-kinase in insulininduced glucose transport and antilipolysis in rat adipocytes. J Biol Chem 269: 3568-3573

10. Quon MJ, Chen H, Ing BL, Liu ML, Zarnowski MJ, Yonezawa K, Kasuga M, Cushman SW, Taylor SI (1995) Roles of 1-phosphatidylinositol 3-kinase and ras in regulating translocation of GLUT4 in transfected rat adipose cells. Mol Cell Biol 15: 5403-5411

11. Tsakiridis T, McDowell H, Walker T, Downes P, Hundal HS, Vranic M, Klip A (1995) Multiple roles of phosphatidylinositol 3-kinase in regulation of glucose transport, amino acid transport, and glucose transporters in L6 skeletal muscle cells. Endocrinology 136: 4315-4322

12. Shepherd PR, Siddle K, Nave BT (1997) Is stimulation of class-I phsophatidylinositol 3-kinase activity by insulin sufficient to activate pathways involved in glucose metabolism. Biochem Soc Trans 25: 978-981

13. Hajduch E, Alessi DR, Hemmings BA, Hundal HS (1998) Constitutive activation of protein kinase $\mathrm{B} \alpha$ by membrane targeting promotes glucose and system A amino acid transport, protein synthesis, and inactivation of glycogen synthase kinase 3 in L6 muscle cells. Diabetes 47: 1006-1013

14. Ueki K, Yamamoto-Honda R, Kaburagi Y, Yamauchi T, Tobe K, Burgering BM, Coffer PJ, Komuro I, Akanuma Y, Yazaki Y, Kadowaki T (1998) Potential role of protein kinase $\mathrm{B}$ in insulin-induced glucose transport, glycogen synthesis, and protein synthesis. J Biol Chem 273: 5315-5322

15. Kohn AD, Summers SA, Birnbaum MJ, Roth RA (1996) Expression of a constitutively active Akt Ser/Thr kinase in 3T3-L1 adipocytes stimulates glucose uptake and glucose transporter 4 translocation. J Biol Chem 271: 31372-31378

16. Cong LN, Chen H, Li YH, Zhou LX, McGibbon MA, Taylor SI, Quon MJ (1997) Physiological role of Akt in insulinstimulated translocation of GLUT4 in transfected rat adipose cells. Mol Endocrinol 11: 1881-1890

17. Wang Q, Somwar R, Bilan P, Liu Z, Jing J, Woodgett J, Klip A (1999) Protein kinase B (PKB)/Akt participates in GLUT4 translocation by insulin in L6 myoblasts. Mol Cell Bio 19: 4008-4018

18. Kahn BB (1992) Facilitative glucose transporters:regulatory mechanisms and dysregulation in diabetes. J Clin Invest 89: 1367-1374

19. Ashcroft FM (1996) Mechanisms of the glycaemic effects of sulphonylureas. Horm Metab Res 28: 456-463 
20. Hirshman MF, Horton ES (1990) Glyburide increases insulin sensitivity and responsiveness in peripheral tissues of the rat as determined by the glucose clamp technique. Endocrinology 126: 407-411

21. Jackson RA, Hawa MI, Jaspan JB, Sim BM, Disilvio L, Featherbe D, Kurtz AB (1987) Mechanism of metformin action in non-insulin-dependent diabetes. Diabetes 36: 632-640

22. Saltiel AR, Olefsky JM (1996) Thiazolidinediones in the treatment of insulin resistance and Type 2 diabetes. Diabetes 45: 1661-1669

23. Packer L, Witt E, Tritschler H (1995) alpha-Lipoic acid as a biological antioxidant. Free Radic Biol Med 19: 227-250

24. Packer L, Roy S, Sen C (1996) alpha-Lipoic acid:a metabolic antioxidant and potential redox modulator of transcription. Adv Pharmacol 38: 79-101

25. Ziegler D, Hanefeid M, Ruhnau K, Meibner H, Lobisch M, Schutte K, Gries F (1996) Treatment of symptomatic diabetic peripheral neuropathy with the anti-oxidant alpha-lipoic acid. Diabetologia 38: 1425-1433

26. Jacob S, Streeper R, Fogt D, Hokama J, Tritschler H, Dietze G, Henriksen E (1996) The antioxidant alpha lipoic acid enhances insulin-stimulated glucose metabolism in insulinresistant rat skeletal muscle. Diabetes 45: 1024-1029

27. Henriksen EJ, Jacob S, Streeper RS, Fogt DL, Hokama JY, Tritschler HJ (1997) Stimulation by alpha-lipoic acid of glucose transport activity in skeletal muscle of lean and obese Zucker rats. Life Sci 61: 805-812

28. Khamaisi M, Potashnik R, Tirosh A, et al. (1997) Lipoic acid reduces glycaemia and increases muscle GLUT4 content in streptozotocin-diabetic rats. Metabolism 46: 763-768

29. Jacob S, Henriksen E, Schiemann A, Simon I, Clancy D, Tritschler H, Jung W, Augustin H, Dietze G (1995) Enhancement of glucose disposal in patients with type 2 diabetes by alpha-lipoic acid. Arzeimittelforschung 45: 872-874

30. Jacob S, Henriksen E, Tritschler H, Augustin H, Dietze G (1996) Improvement of insulin-stimulated glucose disposal in type 2 diabetes after repeated parenteral administration of thioctic acid. Exp Clin Endocrinol Diabetes 104: 284-288

31. Konrad T, Vicini P, Kusterer K, et al. (1999) alpha-Lipoic acid treatment decreases serum lactate and pyruvate concentrations and improves glucose effectiveness in lean and obese patients with type 2 diabetes. Diabetes Care 22: 280-286

32. Haugaard N, Haugaard E (1970) Stimulation of glucose utilization by thioctic acid in rat diaphragm incubated in vitro. Biochim Biophys Acta 222: 583-586

33. Strodter D, Lehmann E, Lehmann U, Tritshcler HJ, Bretzel RG, Federlin K (1995) The influence of thioctic acid on metabolism and function of the diabetic heart. Diabetes Res Clin Pract 29: 19-26

34. Estrada DE, Ewart HS, Tsakiridis T, et al. (1996) Stimulation of glucose uptake by the natural coenzyme $\alpha$-lipoic acid thioctic acid - Participation of elements of the insulin signaling pathway. Diabetes 45: 1798-1804

35. Student AK, Hsu RY, Lane MD (1980) Induction of fatty acid synthetase synthesis in differentiating 3T3-L1 preadipocytes. J Biol Chem 255: 4745-4750

36. Piper RC, Hess LJ, James DE (1991) Differential sorting of two glucose transporters expressed in insulin-sensitive cells. Am J Physiol 260: C570-C580

37. Sargeant RJ, Liu Z, Klip A (1995) Action of insulin on $\mathrm{Na}^{+}-$ $\mathrm{K}^{+}$-ATPase and the $\mathrm{Na}^{+}-\mathrm{K}^{+}-2 \mathrm{Cl}^{-}$cotransporter in 3T3-L1 adipocytes. Am J Physiol 269: C217-C225
38. Somwar R, Sumitani S, Taha C, Sweeney G, Klip A (1998) Temporal activation of p70 S6 kinase and Akt1 by insulIn: PI3k-dependent and -independent mechanisms. Am J Physiol 275: E618-E625

39. Walsh JP, Caldwell KK, Majerus PW (1991) Formation of phosphatidylinositol 3-phosphate by isomerization from phosphatidylinositol 4-phosphate. Proc Natl Acad Sci USA 88: 9184-9187

40. Somwar R, Sweeney G, Ramlal T, Klip A (1998) Stimulation of Glucose and Amino Acid Transport and Activation of the Insulin Signaling Pathways by Insulin Lispro in L6 Skeletal Muscle Cells. Clin Ther 20: 125-140

41. Kupriyanova T, Kandor K (1999) Akt-2 binds to Glut-4containing vesicles and phosphorylates their component proteins in response to insulin. J Biol Chem 274: 1458-1464

42. Sun XJ, Pons S, Wang LM, et al. (1997) The IRS-2 gene of murine chromosome 8 encodes a unique signaling adapter for insulin and cytokine action. Mol Endocrinol 11: 251-262

43. Yang J, Clarke JF, Ester CJ, et al. (1996) Phosphatidylinositol 3-kinase acts at an intracellular membrane site to enhance GLUT4 exocytosis in 3T3-L1 cells. Biochem J 313: 125-131

44. Zhou LX, Chen H, Lin CH, et al. (1997) Insulin receptor substrate-2 (IRS-2) can mediate the action of insulin to stimulate translocation of GLUT4 to the cell surface in rat adipose cells. J Biol Chem 272: 29829-29833

45. White MF (1997) The insulin signalling system and the IRS proteins. Diabetologia 40: S2-S17

46. Klip A, Volchuk A, Ramlal T, Ackerley C, Mitsumoto Y (1994) Glucose transporters of muscle cells in culture:developmental regulation and modulation by lipoic acid, an anti-hyperglycemic agent. Mol Biol Diabetes: 511-528

47. Clarke JF, Young PW, Yonezawa K, Kasuga M, Holman GD (1994) Inhibition of the translocation of GLUT1 and GLUT4 in 3T3-L1 cells by the PI3K inhibitor, wortmannin. Biochem J 300: 631-635

48. Yeh J, Gulve E, Rameh L, Birnbaum M (1995) The effects of wortmannin on rat skeletal muscle:dissociation of signaling pathways for insulin- and contraction-activated hexose transport. J Biol Chem 270: 2107-2111

49. Hara K, Yonezawa K, Sakaue H, et al. (1994) 1-Phosphatidylinositol 3-kinase activity is required for insulin-stimulated glucose transport but not for RAS activation in $\mathrm{CHO}$ cells. Proc Natl Acad Sci, USA 91: 7415-7419

50. Katagiri H, Asano T, Ishihara H, et al. (1996) Overexpression of catalytic subunit $\mathrm{p} 110 \alpha$ of phosphatidylinositol 3-kinase increases glucose transport activity with translocation of glucose transporters in 3T3-L1 adipocytes. J Biol Chem 271: $16987-16990$

51. Tanti JF, Gremeaux T, Grillo S, et al. (1996) Overexpression of a constitutively active form of phosphatidylinositol 3 -kinase is sufficient to promote glut-4 translocation in adipocytes. J Biol Chem 271: 25227-25232

52. Tsakiridis T, Vranic M, Klip A (1995) Phosphatidylinositol 3-kinase and the actin network are not required for the stimulation of glucose transport caused by mitochondrial uncoupling: comparison with insulin action. Biochem. J 309: 1-5

53. Paquet MR, Romanek RJ, Sargeant RJ (1992) Vanadate induces the recruitment of GLUT-4 glucose transporter to the plasma membrane of rat adipocytes. Mol Cell Biochem 109: $149-155$

54. Tsiani E, Bogdanovic E, Sorisky A, Nagy L, Fantus GI (1998) Tyrosine phosphatase inhibitors, vanadate and pervanadate, stimulate glucose transport and GLUT translocation in muscle cells by a mechanism independent of phos- 
phatidylinositol 3-kinase and protein kinase C. Diabetes 47: 1676-1685

55. Kotani K, Ogawa W, Matsumoto M, et al. (1998) Requirement of atypical protein kinase $\mathrm{Cl}$ for insulin stimulation of glucose uptake but not for Akt activation in 3T3-L1 adipocytes. Mol Cell Bio 18: 6971-6982

56. Paolisso G, Giugliano D (1996) Oxidative stress and insulin action:Is there a relationship? Diabetologia 39: 357-363

57. Sano T, Umeda F, Hashimoto T, Nawata H, Utsumi $H$ (1998) Oxidative stress measurement by in vivo electron spin resonance in rats with streptozotocin-induced diabetes. Diabetologia 41: 1355-1360

58. Traverso N, Menini S, Cosso L, Odetti P, Albano E, Pronzato M, Marinari U (1998) Immunological evidence for increased oxidative stress in diabetic rats. Diabetologia 41: 265-270

59. Rudich A, Tirosh A, Potashnik R, Khamaisi M, Bashan N (1999) Lipoic acid protects against oxidative stress induced impairment in insulin stimulation of PKB and glucose transport in 3T3-L1 adipocytes. Diabetologia 42: 949-957 